\title{
Development and validation of a brief general and sports nutrition knowledge questionnaire and assessment of athletes' nutrition knowledge
}

Gina Louise Trakman ${ }^{1 *}$, Adrienne Forsyth $^{1}$, Russell Hoye ${ }^{2}$ and Regina Belski ${ }^{3}$

\begin{abstract}
Background: The Nutrition for Sport Knowledge Questionnaire (NSKQ) is an 89-item, valid and reliable measure of sports nutrition knowledge (SNK). It takes 25 min to complete and has been subject to low completion and response rates. The aim of this study was to develop an abridged version of the NSKQ (A-NSKQ) and compare response rates, completion rates and NK scores of the NSKQ and A-NSKQ.

Methods: Rasch analysis was used for the questionnaire validation. The sample $(n=181)$ was the same sample that was used in the validation of the full-length NSKQ. Construct validity was assessed using the known-group comparisons method. Temporal stability was assessed using the test-retest reliability method. NK assessment was cross-sectional; responses were collected electronically from members of one non-elite Australian football (AF) and netball club, using Qualtrics Software (Qualtrics, Provo, UT).

Results: Validation - The A-NSKQ has 37 items that assess general $(n=17)$ and sports $(n=20)$ nutrition knowledge (NK). Both sections are unidimensional (Perc5\% $=2.84 \%$ [general] and 3.41\% [sport]). Both sections fit the Rasch Model (overall-interaction statistic mean (SD) $=-0.15 \pm 0.96$ [general] and $0.22 \pm 1.11$ [sport]; overall-person interaction statistic mean (SD) $=-0.11 \pm 0.61$ [general] and $0.08 \pm 0.73$ [sport]; Chi-Square probability $=0.308$ [general] and 0.283 [sport]). Test-retest reliability was confirmed $(r=0.8, P<0.001$ [general] and $r=0.7, P<0.001$ [sport]). Construct validity was demonstrated (nutrition students $=77 \%$ versus non-nutrition students $=60 \%, \mathrm{P}<0.001$ [general] and nutrition students $=60 \%$ versus non-nutrition students $=40 \%, \mathrm{P}<0.001$ [sport]. Assessment of NK -177 usable survey responses from were returned. Response rates were low (7\%) but completion rates were high (85\%). NK scores on the A-NSKQ (46\%) are comparable to results obtained in similar cohorts on the NSKQ (49\%). The A-NSKQ took on average 12 min to complete, which is around half the time taken to complete the NSKQ (25 min).
\end{abstract}

Conclusions: The A-NSKQ is a valid and reliable, brief questionnaire designed to assess general NK (GNK) and SNK. Keywords: Sport, Nutrition knowledge, Knowledge, Food, Diet, Athlete, Questionnaires, Response rate, Completion rate

\footnotetext{
* Correspondence: G.trakman@latrobe.edu.au

'Department of Rehabilitation, Nutrition and Sport, School of Allied Health, College of Science, Health and Engineering, La Trobe University, Melbourne 3086, Australia

Full list of author information is available at the end of the article
}

(C) The Author(s). 2018 Open Access This article is distributed under the terms of the Creative Commons Attribution 4.0 International License (http://creativecommons.org/licenses/by/4.0/), which permits unrestricted use, distribution, and reproduction in any medium, provided you give appropriate credit to the original author(s) and the source, provide a link to the Creative Commons license, and indicate if changes were made. The Creative Commons Public Domain Dedication waiver (http://creativecommons.org/publicdomain/zero/1.0/) applies to the data made available in this article, unless otherwise stated. 


\section{Background}

Nutrition knowledge (NK) is a modifiable determinant of dietary behaviour $[1,2]$ and dietary practices are known to influence athletic performance [3]. Therefore, there has been much interest in the assessment of athletes' general nutrition knowledge (GNK) and sports nutrition knowledge (SNK) $[4,5]$. There are limitations with some of the NK questionnaires that have previously been employed, including testing outdated recommendations, lack of comprehensiveness, lack of cultural appropriateness, and insufficient validation [6]. The issue of inadequate validation is common in evaluation measures used in nutrition education research [7]. Researchers may overlook comprehensive methodologies because the time taken to develop and validate questionnaires can be prohibitive [8].

The Nutrition for Sport Knowledge Questionnaire (NSKQ) [9] was developed in 2017 and overcame many of the aforementioned limitations. The NSKQ was based on current sports nutrition recommendations $[10,11]$ and is comprehensive, containing 89 questions across six nutrition sub-sections. Moreover, it was developed with a panel of international sports dietitians and validated using a robust methodology that included both Classical Test Theory (CTT) [8] and Rasch analysis [12].

Other recently developed SNK questionnaires also represent an improvement on previous tools and are of similar length to the NSKQ [13-15]. When collecting data to assess the validity of the NSKQ [9], and (later) when using the NKSQ to evaluate Australian Footballers' NK ${ }^{1}$ response and completion rates were low. The NSKQ takes athletes on average $25 \mathrm{~min}$ to complete. Some researchers have reported that the ideal questionnaire completion time to optimise response rates is $13 \mathrm{~min}$ or less [16]. Galesic et al. [17] reported that, in general, online-questionnaires that were perceived to be long were started and completed by fewer respondents, with less time spent on questions at the end of questionnaires. In contrast, a meta-analysis of factors influencing response rates of online-questionnaires found that questionnaire length had a very small effect $(r=0.001)$ on response rates [18], but the paper did not report on completion rates.

To our knowledge, there is no published data specifically on the effect of questionnaire length on response and completion rates in athletic cohorts. Both elite and non-elite sportspeople are often pressed for time, balancing busy training schedules with other commitments [19]. Therefore, it is feasible that long questionnaires would be daunting to athletes and the professionals working with them, and in part, explain the low response and completion rates of the NSKQ.

The aforementioned factors demonstrate a potential need for shorter measurement tools to assess NK amongst athletes. Appropriate validation of such tools is critical if they are to be used by dietitians and coaches with the intention of influencing athlete behaviour and ultimately performance. Rasch analysis is a method which allows researchers to produce short measurement tools that include both difficult and simple items, and is therefore a suitable method for use in developing a brief NK questionnaire [20]. The Rasch model presumes individuals with higher levels of knowledge are more likely to obtain a high NK score and that easy items are more likely to be answered correctly by all respondents [20]. This is advantageous because it means the focus of validation is on the questionnaire as a whole, rather than on individual items [21].

The aims of this study were to:

1. re-assess data used to validate the NSKQ to develop an abridged version of the questionnaire (the ANSKQ) and

2. compare and contrast response rates, completion rates and NK scores between NSKQ and A-NSKQ in a cohort of non-elite AF and netball athletes.

It was hypothesised that the A-NSKQ would achieve higher completion rates than the NSKQ, and produce NK scores that are comparable to a related cohort (nonelite AF players).

\section{Methods}

\section{Institutional review board}

The research was approved (S16/267) by the La Trobe University's SHE College Human Ethics Sub-Committee (SHE CHESC). All participants were provided with the participant information statement and consent form (online) and 'agreed' to participate (electronically).

\section{Instrument development}

The data used to develop the abridged version of the NSKQ was the same data that was collected for the final stages of the full-length NSKQ validation. Participants $(n=181)$ were Australian athletes and university students, recruited from November 2016 to January 2017 [9]. The sample was predominately female (75\%), aged 17-25 (52\%), born in Australia (81\%), and university educated (96\%) (Additional file 1: Table S1).

A detailed description of the development and validation of the full-length NSKQ are described elsewhere [9]. The full-length NSKQ was developed in accordance with methods recommended by Trakman et al. [6], and the validation of the A-NSKQ was based on a modified version of these methods. In the validation of the A-NSKQ no new items were developed (steps $1-3$ ) and face and content validity (steps 4 and 5) were not re-assessed (Table 1). 
Table 1 Comparison of methods used in the development and validation of the NSKQ and A-NSKQ

\begin{tabular}{|c|c|}
\hline NSKQ development and validation & A-NSKQ validation \\
\hline $\begin{array}{l}\text { Development of the tool: } \\
\text { 1. Define construct and develop test plan. 2. Generate items. 3. Choose scoring system } \\
\text { Preliminary review of the items: } \\
\text { 4. Assess content validity. 5. Asses face validity } \\
\text { Further statistical analysis of measurement: } \\
\text { 6. Purification of the scale using item analysis } \\
\text { 7. Evaluate internal reliability and use of Rash analysis to assess item/person indicators, } \\
\text { dimensionality and internal reliability } \\
\text { Final analysis: } \\
\text { 8. Re-examine questionnaire properties, assess temporal stability and confirm construct } \\
\text { validity. }\end{array}$ & $\begin{array}{l}\text { Using data from step (8) } \\
\text { 1. Rash analysis to assess item/person indicators, } \\
\text { dimensionality and internal reliability } \\
\text { 2. Assess temporal stability and construct validity, } \\
\text { using proxy-scores. }\end{array}$ \\
\hline
\end{tabular}

Item analysis (step 6) was performed using Rasch analysis only. Rasch analysis was conducted using RUMM2030 Professional software. The aim of this step was to remove items that were causing misfit to the Rasch model. Misfit was assessed based on overall iteminteraction, overall person-interaction and overall itemtrait interaction. A SD of 1 and mean of 0 for overallitem and overall-person interaction, and non-significant Chi-Square probability for overall item-trait interaction indicate compliance with the Rasch model (i.e. no misfit). In order to determine which items (or persons) were causing misfit, the following indicators were evaluated: individual item fit residuals, item characteristic curves (ICC), category probability curves (CPC) and differential item functioning (DIF). Detailed definitions and interpretation of the aforementioned statistics are beyond the scope of this report, but are described elsewhere $[6,12]$ and summarised in Additional file 1: Table S2. Stricter criteria were applied during item analysis for validation of the A-NSKQ. During the validation of the full-length NSKQ the researchers retained certain items that did not meet one or two of the aforementioned Rasch indicators because they were deemed relevant in terms of assessing gaps in $\mathrm{NK}$ and retaining content validity. However, in the validation of the A-NSKQ, all items that failed on a single indicator were excluded.

Assessment of internal reliability and dimensionality (step 7) were also performed using Rasch analysis only for the validation of the A-NSKQ. Reliability was assessed using the PerSepIndex, a summary statistic produced by RUMM 2030 that is analogous to Cronbach $\alpha$. Both PerSepIndex and $\mathrm{C} \alpha$ are based on repeated splithalf reliability assessment; a value of $\geq 0.7$ is an acceptable measure of internal reliability [12]. Dimensionality was assessed using the perc $5 \%$ statistic; values of $5 \%$ or less indicate unidimensionality, a requirement of the Rasch model [20].

Gathering of new data to re-examine the scale (step 8) was not conducted. Rather, a 'proxy score' for each respondent was calculated by subtracting the deleted NSKQ items from participants' original score. Similar methods were used by past researchers [22] to compare scores on the original and revised General Nutrition Knowledge Questionnaire (GNKQ/R-GNKQ). Using the proxy scores, construct validity was assessed using the known-group comparisons method and temporal stability was assessed using the test-retest reliability method (Table 1). For the known-group comparisons assessment, NK (proxy) scores of individuals with and without a formal nutrition education (university course, university subject, diploma, and online course) were compared; statistically significant differences are indicative of construct validity [6]. For the test-retest reliability assessment the correlation of NK (proxy) scores on two attempts of the questionnaire, taken ten days to two weeks apart, were assessed; a correlation of $\geq 0.7$ indicates temporal stability [6]. The correlation between NK proxy scores and original scores was also assessed.

\section{Athletes' nutrition knowledge}

After the NSKQ had been revised and the A-NSKQ had been validated, it was administered to Australian nonelite athletes. Members $(n=3951)$ of one metropolitan AF and netball league in Melbourne, Australia were invited (via email from the league president) to participate in the study by completing the A-NSKQ online. Interested and eligible (residing in Australia, aged 17 years and older) players completed the survey using Qualtrics Research Suite (Qualtrics, Provo, Utah) from May to April 2017.

\section{Data analysis}

All analyses (aside from questionnaire validation) were performed in SPSS (Version 23; SPSS, Chicago, IL, USA). Scores on the A-NSKQ and time taken to complete the A-NSKQ were assessed for normality using the Kolmogorov-Simonov statistic. Chi-Square goodness of fit tests were used to evaluate differences in (categorical) demographic characteristics across gender, sport played, highest level of education, previous history of nutrition education, and highest level sport played. Differences in $\mathrm{NK}$ scores were assessed using t-test or 
ANOVA for parametric data, and Mann-Whitney-U-test or Kruskal-Wallis for non-normal data. Significant differences in questionnaire sub-section scores were assessed using paired sample t-test or Wilcoxon-signed-rank-test. The alpha value for most tests was set at $P \leq 0.05$. A Bonferroni correction was applied to Kruskal-Wallis tests, and $\mathrm{P}$ was set at $\leq 0.017$. Respondents with more than $10 \%$ missing data were removed from analysis. Missing responses to items were coded as incorrect.

\section{Results}

\section{Instrument development}

The original NSKQ consisted of 89 items. Rasch analysis showed that three items had high fit residuals, 19 items had problematic CPCs, 38 items had problematic ICCs, and one item showed DIF (for country). Nine items failed on two indicators, therefore, in total, 52 items were problematic and were excluded from the A-NSKQ, leading to a 37-item questionnaire.

The A-NSKQ was not unidimensional $($ Perc5\% $=7$. $39 \%)$. The two sub-sets of items that were most different from each other, based on principal components analysis (PCA), were not theoretically related. Therefore, the investigator (GT) divided the items into two sub-sections based on their content. The first sub-section ('general nutrition knowledge') included 17 items that assessed knowledge of energy density; the role and sources of macronutrients and micronutrients; and alcohol. The second section ('sports nutrition knowledge') included 20 items that assessed knowledge of athletes' macronutrient and fluid requirements; weight loss and gain strategies for athletes; and supplementation for athletes. These two sub-sections fit the Rasch model and were unidimensional. Reliability of the whole scale (PerSepIndex $=0.8$ ) and the SNK (PerSepIndex $=0.7$ ) were acceptable; the value for the GNK (PerSepIndex =0.6) was below the requisite value of 0.7 (Table 2).

Individuals who had undertaken nutrition studies scored better in the GNK and SNK sub-sections (nutrition students $=77 \%$ versus non-nutrition students $=60 \%$, $P<0.001[\mathrm{GNK}]$ and nutrition students $=60 \%$ versus non-nutrition students $=40 \%, \quad \mathrm{P}<0.001 \quad[\mathrm{SNK}])$, indicating construct validity. Test re-test reliability was demonstrated based on the proxy scores $(r=0.8, P<0$. 001 [GNK] and $r=0.7, P<0.001$ [SNK]). There was a strong, positive correlation $(r=0.9, \mathrm{P}<0.001)$ between individuals' score (\%) on the NSKQ and their proxy score on the A-NSKQ. This indicates the removal of the items did not alter overall total (\%) NK scores.

\section{A-NSKQ response and completion rates}

Two-hundred-and-seventy-three athletes followed the link to complete the A-NSKQ (response rate $=7 \%$ ). The individual response rate of the NSKQ could not be calculated for non-elite athletes, because the questionnaire was distributed by a second party and the total number of invitations was not known; the response rate for team presidents who agreed to distribute the NSKQ was 813\% (Additional file 1: Table S2).

After deleting responses of individuals who followed the link but did not agree to the participant information and consent form $(n=65$; not included in completion rate calculations), incomplete responses $(n=22)$ and respondents who did not meet the eligibility criteria for age $(n=9)$, there were 177 usable responses. The completion rate for the A-NSKQ (85\%) was higher than the average completion rate for the NSKQ (54\%); completion rate calculations were undertaken in the same manner (Additional file 1: Table S2).

The median time taken to complete the A-NSKQ was $12 \mathrm{~min}$, compared to $25 \mathrm{~min}$ taken to complete the NSKQ.

\section{A-NSKQ participant characteristics}

The characteristics of the participants who completed the A-NSKQ are outlined in Table 3. The sample was predominately female (61\%) and aged $17-25$ years (48\%). Despite being distributed to the database of a recreational $\mathrm{AF}$ and netball league, $23 \%$ of athletes stated the main sport they played was not AF or netball, and $19 \%$ of athletes reported competing at the state, national or international level.

There were no differences in age, gender, country of birth, level of education and previous nutrition study

Table 2 Summary of properties of the A-NSKQ

\begin{tabular}{|c|c|c|c|c|c|c|c|}
\hline $\begin{array}{l}\text { Section (number } \\
\text { of questions) }\end{array}$ & $\begin{array}{l}\text { Overall-item } \\
\text { interaction statistics } t \\
\text { (Mean } \pm \text { SD) }\end{array}$ & $\begin{array}{l}\text { Overall-person } \\
\text { interaction statistics } † \\
\text { Mean (SD) }\end{array}$ & $\begin{array}{l}\text { Chi-Square } \\
\text { probability } \neq \\
\text { ( } P \text {-value) }\end{array}$ & Perc5\% & $\begin{array}{l}\text { Person } \\
\text { Separation } \\
\text { Index } ¥\end{array}$ & $\begin{array}{l}\text { Test-retest } \\
\text { reliability } ¥ \\
\text { (Pearson's r) }\end{array}$ & Score (\%) \\
\hline Total $(n=37)$ & $0.04 \pm 0.90$ & $0.01 \pm 0.74$ & 0.076 & 7.39 & 0.8 & $0.7^{*}$ & $\begin{array}{l}\text { Nutrition: } 66+/-14 \\
\S \text { Non-nutrition: } 52+/-13^{*}\end{array}$ \\
\hline General $(n=17)$ & $-0.15 \pm 0.96$ & $-0.11 \pm 0.61$ & 0.308 & 2.84 & 0.6 & $0.8^{*}$ & $\begin{array}{l}\text { Nutrition: } 77 \text { (24) } \\
\text { II Non-nutrition: } 65 \text { (25) * }\end{array}$ \\
\hline Sports $(n=20)$ & $0.22 \pm 1.11$ & $-0.08 \pm 0.73$ & 0.283 & 3.41 & 0.7 & $0.7^{*}$ & $\begin{array}{l}\text { II Nutrition: } 60 \text { (25) } \\
\text { Non-nutrition: } 40 \text { (21)* }\end{array}$ \\
\hline
\end{tabular}

† Mean $\pm \mathrm{SD}=0 \pm 1$ = perfect fit; $\mathrm{SD}>1.5=$ misfit. $¥$ Non-significant $p$-value $=$ fit. $\emptyset<5 \%=$ unidimensionality. $¥$ PerSeplndex $>0.7=$ adequate internal reliability. $¥ r \geq$ $0.7=$ test-retest reliability. $\S$ Score reported as mean $+/-$ SD. II score reported as median (IQR) $*=<0.001$ 
between those who reported playing at the elite and non-elite level. However, individuals who reported playing a sport other than AF as their primary sport were more likely to play at higher levels of competition $\left(X^{2}=104.526, \mathrm{df}=1, P<0.001\right)$. Females were more likely to play a sport other than $\operatorname{AF}\left(X^{2}=4.637, \mathrm{df}=\right.$ $1, P=0.031)$ and to be university educated $\left(X^{2}=0\right.$. 337, $\mathrm{df}=1 . \mathrm{P}<0.001)$.

\section{Nutrition knowledge of athletes \\ Knowledge scores}

The mean total score was $47 \pm 12 \%$. There was a large variability amongst participants and between SNK and GNK (Table 4).

Table 3 Participant characteristics of individuals who completed the A-NSKQ

\begin{tabular}{ll}
\hline Age, n (\%) & \\
$17-25$ & $85(48)$ \\
$26-35$ & $66(37)$ \\
$\geq 36$ & $26(15)$ \\
Gender, n (\%) & \\
Male & $69(39)$ \\
Female & $108(61)$ \\
Country of Birth, n (\%) & \\
Australia & $167(94)$ \\
Outside Australia & $10(6)$ \\
Highest Level of Education, n (\%) & \\
High School & $32(18)$ \\
Diploma & $28(16)$ \\
University & $117(66)$ \\
Formal Nutrition Studies, n (\%) & \\
Yes & $37(21)$ \\
No & $140(79)$ \\
Sport Played, n (\%) & \\
AF & $23.9(4.5)$ \\
Netball & \\
Other & \\
Highest level of sport played, n (\%) & \\
Metropolitan (Non-elite) & $129(73)$ \\
State (Non-elite) & $8(5)$ \\
National (Elite) & \\
International (Elite) & $40(23)$ \\
Years Playing Sport, Median (IQR) \\
\hline
\end{tabular}

\section{Responses to individual items and gaps in knowledge}

Several misconceptions were evident, especially with regards to hydration, micronutrients and supplementation. For example, only $8 \%$ of athletes knew that they should drink to maintain plasma volume and 94\% thought that vitamin B1 was needed for delivery of oxygen to tissues'. In contrast, questions on the role and sources of fat, the effect of alcohol on performance and post-exercise snacks were answered correctly by more than $70 \%$ of participants (Additional file 1: Table S4).

\section{Individual characteristics and knowledge}

Stratified results based on individual characteristics are reported in Additional file 1: Table S5. Individuals with a formal nutrition education scored significantly higher in both the SNK $(P=0.003)$ and GNK $(P=0.003)$ section. There was a significant difference in SNK $(P=0.037)$ and GNK $(P=0.003)$ based on level of education. For GNK and SNK, when a Bonferroni correction was applied, only the difference between high school and diploma was statistically significant; $P=0.013[\mathrm{GNK}]$ and $(P=0.0011)$ [SNK]. There was also a significant difference in GNK based on age $(P=0.013)$. Individuals aged $\geq 36$ scored statistically significantly higher than those aged 17-25 $(P=0$. 004) and those aged 26-35 $(P=0.003)$.

\section{Discussion}

The aims of this study were to (1) re-assess data used to validate the NSKQ to develop an abridged version of the questionnaire (the A-NSKQ) and (2) compare and contrast response rates, completion rates and NK scores between NSKQ and A-NSKQ in a cohort of non-elite $\mathrm{AF}$ and netball athletes. The authors hypothesized that the A-NSKQ would achieve similar results to, but higher completion rates than, the NSKQ.

\section{The instrument}

The 37-item A-NSKQ can be completed in around half the time taken to complete the NSKQ (12 versus $25 \mathrm{~min}$ ). The A-NSKQ covers the same key topics assessed in the NSKQ (weight management, macronutrients, micronutrients, supplementation, sport nutrition, and alcohol);however, it does not evaluate some aspects of these topics, such as the role of specific supplements, and the consequences of dehydration. Therefore, the content and face validity of the A-NSKQ should be

Table 4 Scores on the A-NSKQ

\begin{tabular}{llll}
\hline Section & Total Score (\%) & Minimum Score (\%) & Maximum Score (\%) \\
\hline Total & $+47 \pm 12$ & 8 & 78 \\
GNK & $\neq 59(18)^{*}$ & 18 & 82 \\
SNK & $\neq 35(18)^{*}$ & 0 & 70 \\
\hline
\end{tabular}


reviewed by individuals planning on using the tool, to ensure that it serves their intended purpose.

The results of this study show that the A-NSKQ subsections (GNK and SNK) fit the Rasch model, indicating that the items meet the requirements that difficult questions are less likely to be answered correctly and individuals with higher levels of NK are more likely to perform well [20]. Likewise, the questionnaire demonstrated testretest reliability and achieved or approached predetermined cut-off values for internal reliability. However, a limitation is that these assessments were based on proxy scores. Construct validity was also determined based on the proxy scores, and was confirmed when the A-NSKQ was administered to non-elite athletes, as those with previous nutrition education scored significantly higher than those without any formal nutrition education (Additional file 1: Table S5). The criterion validity of the A-NKSQ could be assessed in future studies by administrating both questionnaires to participants and calculating the correlation between scores (\%). However, it may be difficult to achieve adequate response rates for this step, as respondents are likely to find completing both tools burdensome. In addition, participants may research the correct answers to questions before the second completion, which would influence the validity of this method.

\section{Response and completion rates}

The invitation to complete the A-NSKQ was distributed to a large number of non-elite athletes via email, but response rates were low (7\%). Although web-surveys are known to have lower response rates than mail-based surveys, these usually sit around 34\% [23]. Response rates for NSKQ could not be calculated because it was distributed via Facebook groups and online forums, or via second parties where total exposure was not known. However, the percentage of non-elite teams who responded positively to be involved in data collection using the NSKQ (6-13\%) was very similar to the response rates of individuals who participated in data collection using the A-NSKQ (7\%). This is in line with some reports in the literature that questionnaire length has only a small effect on response rates [18]. Although the shorter length did not appear to have a positive effect on response rates, it did have a positive effect on completion rates. Completion rates in the present study were $85 \%$, which is higher than completion rates $(54 \%)$ achieved during the validation and use of NSKQ to collect data. As above, this finding is akin to what has previously been reported regarding questionnaire length and completion rates [17]. Future studies should consider distribution methods and survey design to ensure that response and completion rates are optimised. These include designing personalised invitations and sending reminders and notifications if responses have not been obtained [16]. However, personal interest in the topic is one of the key factors influencing individuals' decision to participate in a survey, and this cannot be controlled by investigators [16].

\section{Nutrition knowledge of athletes}

The results indicate there is room for improvement in non-elite AF and netball players' NK. Athletes' mean score was 47\%; similarly, non-elite, male AF players scored $51 \%$ on the NSKQ ${ }^{1}$. In the present study, athletes performed much better on questions of GNK than SNK, which is akin to results reported by Devlin et al. [24] and Kunkel et al. [25], but in contrast to results reported by Harrison et al. [26] and Barr [27]. Respondents answered items on hydration (q27) supplements (q35, q26, and q37) and micronutrients (q13, q 23, and q25) poorly. These items were also answered poorly when the NSKQ was administered to non-elite AF players ${ }^{1}$. In the existing literature there are inconsistencies regarding gaps in knowledge with some studies reporting hydration [28], supplementation [29] and micronutrients [28] were better understood than other topics, and others finding the opposite to be true [26, 30].

A literature review undertaken by Trakman et al. [31] reported that $64 \%$ of studies on athletes' and coaches' NK found that prior nutrition knowledge, higher levels of education, previously undertaking a nutrition course or currently majoring in nutrition studies correlated with higher NK scores. Ten of fifteen studies that assessed the effects of gender on NK stated there were no significant differences between males and females. All studies that evaluated sporting calibre and type of sport reported these had no effect on NK scores. The present study reflected these findings; previous nutrition education and higher levels of education positively affected NK score, but a relationship between score and sport played, sporting level and gender were not detected. Older participants had better GNK, which is in contrast to findings in other cohorts [32]. Of note, however, the current sample had only a small proportion of athletes from sports other than AF, and playing at the sub-elite or elite level.

\section{Conclusions}

The findings of this study confirm that there is room for improvement in athletes' NK. Professionals working with athletes should provide targeted advice based on nutrition topics that are poorly understood and education programs should be evaluated using validated NK measures [33]. Long SNK questionnaires are beneficial for their ability to assess gaps in NK but shorter questionnaires appear to achieve higher completion rates amongst athletes, and thus may be more practical in 
certain settings. The A-NSKQ is a brief tool to assess GNK and SNK that has been validated against the Rasch model and results in total (\%) scores that are comparable to the NSKQ. Preliminary results using the A-NSKQ indicate that hydration, micronutrients and supplementation are topics where there may be gaps in the knowledge of recreational Australian athletes. The A-NSKQ can be used to assess the NK of athletes and inform additional data collection efforts (i.e. interviews with individual athletes), education programs, or advocate for increased nutrition education by trained professionals.

\section{Endnotes}

${ }^{1}$ Trakman GL, Forsyth A, Middleton K, Jenner S, Keenan A, Hoye R, Belski R. Australian football athletes lack awarenss of current sports nutrition guidelines. Int J Nutr Exerc Metab. 2017; Awaiting DOI.

\section{Additional file}

Additional file 1: Table S1. Characteristics of participants who completed the NSKQ for validation $(n=181)$. Table S2. Summary of RUMM2030 statistics that are assessed to determine reason for misfit to the Rash model. Table S3. Response and completion rates for the NSKQ and A-NSKQ. Table S4. Responses (percent correct) of individual items in the A-NSKQ. Table S5. Differences in NK on the A-NSKQ based on participant characteristics. (DOCX $34 \mathrm{~kb}$ )

\section{Abbreviations}

A-NSKQ: Abridged Nutrition for Sport Knowledge Questionnaire; GNK: General nutrition knowledge; NK: Nutrition knowledge; NKQ: Nutrition knowledge questionnaire; NSKQ: Nutrition for Sport Knowledge Questionnaire; SNK: Sports nutrition knowledge

\section{Acknowledgements}

We would like to thank all the participants who were involved in the various stages of the study. A special thanks to the Sports Dietitians who took part in the expert panel review, and to Dr. Brooke Lea Devlin, who contributed to an internal review of an early version of the questionnaire.

\section{Funding}

This work was supported by an Australian Government Research Training Program Scholarship (GT).

\section{Availability of data and materials}

The data used/and or analyses during the current study are available from the corresponding author on reasonable request. The final version of the ANSKQ is available as supplementary material.

\section{Authors' contributions}

GLT undertook all data analysis, wrote the majority of the manuscript and oversaw participant recruitment and the manuscript preparation. AF assisted with decision making regarding modifications to the questionnaire, participant recruitment, and manuscript preparation. $\mathrm{RH}$ assisted with participant recruitment and manuscript preparation. RB assisted with decision making regarding modifications to the questionnaire, participant recruitment, and manuscript preparation. All authors read and approved the final manuscript.

\section{Ethics approval and consent to participate}

The research was approved (S16/267) by the La Trobe University's SHE College Human Ethics Sub-Committee (SHE CHESC). Participants read the participant information statement and provided consent electronically.

\section{Competing interests}

The authors declare that they have no completing interests.

\section{Publisher's Note}

Springer Nature remains neutral with regard to jurisdictional claims in published maps and institutional affiliations.

\section{Author details}

${ }^{1}$ Department of Rehabilitation, Nutrition and Sport, School of Allied Health, College of Science, Health and Engineering, La Trobe University, Melbourne 3086, Australia. ${ }^{2}$ Office of the Deputy Vice-Chancellor Research, La Trobe University, Melbourne 3086, Australia. ${ }^{3}$ Department of Health Professions, School of Health Science, Faculty of Health, Art and Design, Swinburne University of Technology, Melbourne 3122, Australia.

Received: 17 January 2018 Accepted: 12 April 2018

Published online: 19 April 2018

\section{References}

1. Axelson ML, Brinberg D. The measurement and conceptualization of nutrition knowledge. J Nutr Educ. 1992;5:239-46.

2. Birkenhead $\mathrm{KL}$, Slater $\mathrm{G}$. A review of factors influencing athletes' food choices. Sports Med. 2015;11:1511-22.

3. Rodriguez NR, DiMarco NM, Langley S. Position of the American dietetic association, dietitians of Canada, and the American college of sports medicine: nutrition and athletic performance. J Am Diet Assoc. 2009:3:509-27.

4. Raymond-Barker P, Petroczi A, Quested E. Assessment of nutritional knowledge in female athletes susceptible to the female athlete triad syndrome. J Occup Med Toxicol. 2007;2:10.

5. Abood DA, Black DR, Birnbaum RD. Nutrition education intervention for college female athletes. J Nutr Educ Behav. 2004;3:135-7.

6. Trakman GL, Forsyth A, Hoye R, Belski R. Developing and validating a nutrition knowledge questionnaire: key methods and considerations. Public Health Nutr. 2017:15:2670-9.

7. Contento IR, Randell JS, Basch CE. Review and analysis of evaluation measures used in nutrition education intervention research. J Nutr Educ Behav. 2002;1:2-25.

8. Parmenter K, Wardle J. Development of a general nutrition knowledge questionnaire for adults. Eur J Clin Nutr. 1999:3:298-08.

9. Trakman GL, Forsyth A, Hoye R, Belski R. The nutrition for sport knowledge questionnaire (NSKQ): development and validation using classical test theory and Rasch analysis. J Int Soc Sports Nutr. 2017;1:26.

10. Kreider RB, Wilborn CD, Taylor L, Campbell B, Almada AL, Collins R, Cooke M, Earnest CP, Greenwood M, Kalman DS, Kerksick CM, Kleiner SM, Leutholtz B, Lopez H, Lowery LM, Mendel R, Smith A, Spano M, Wildman R, Willoughby DS, Ziegenfuss TN, Antonio J. ISSN exercise \& sport nutrition review: research \& recommendations. J Int Soc Sports Nutr. 2010;7:7.

11. Potgieter S. Sport nutrition: a review of the latest guidelines for exercise and sport nutrition from the American College of Sport Nutrition, the International Olympic Committee and the International Society for Sports Nutrition. South Afr J Clin Nutr. 2013;1:6-16

12. Pallant J. Scale development, Rasch Analysis and Item Response Theory. In: Melbourne Australian Consortium for Social \& Political Research Inc; 2016.

13. Calella P, lacullo VM, Valerio G. Validation of a general and sport nutrition knowledge questionnaire in adolescents and young adults: GeSNK. Nutrients. 2017:5:439.

14. Furber MJW, Roberts JD, Roberts MG. A valid and reliable nutrition knowledge questionnaire for track and field athletes. BMC Nutrition. 2017:1:36.

15. Heikkilä M, Valve R, Lehtovirta M, Fogelholm M. Development of a nutrition knowledge questionnaire for young endurance athletes and their coaches. Scand J Med Sci Sports. 2017; https://doi.org/10.1111/sms.12987.

16. Fan $W$, Yan Z. Factors affecting response rates of the web survey: a systematic review. Comput Human Behav. 2010;2:132-9.

17. Galesic M, Bosnjak M. Effects of Questionnaire Length on Participation and Indicators of Response Quality in a Web Survey. Public Opin Q. 2009;2:349-36.

18. Cook C, Heath F, Thompson RL. A meta-analysis of response rates in webor internet-based surveys. Educ Psychol Meas. 2000;6:821-36. 
19. Heaney S, O'Connor H, Naughton G, Gifford J. Towards an understanding of the barriers to good nutrition for elite athletes. Int J Sports Sci Coach. 2008; 3:391-401.

20. Pallant JF, Tennant A. An introduction to the Rasch measurement model: an example using the hospital anxiety and depression scale (HADS). Br J Clin Psychol. 2007;1:1-18.

21. Mötteli S, Barbey J, Keller C, Bucher T, Siegrist M. Development and validation of a brief instrument to measure knowledge about the energy content of meals. J Nutr Educ Behav. 2017:3:257-63. e251

22. Spendlove JK, Heaney SE, Gifford JA, Prvan T, Denyer GS, O'Connor HT. Evaluation of general nutrition knowledge in elite Australian athletes. $\mathrm{Br} J$ Nutr. 2012;12:1871-80.

23. Shih T-H, Fan X. Comparing response rates from web and mail surveys: a meta-analysis. Field methods. 2008;3:249-71.

24. Devlin BL, Belski R. Exploring general and sports nutrition and food knowledge in elite male Australian athletes. Int J Sport Nutr Exerc Metab. 2015;3:225-32.

25. Kunkel ME, Bell LB, Luccia BHD. Gem no. 330. Peer nutrition education program to improve nutrition knowledge of female collegiate athletes. J Nutr Educ. 2001;2:114-5.

26. Harrison J, Hopkins W, MacFarlane D, Worsley A. Nutrition knowledge and dietary habits of elite and non-elite athletes. Aust J Nutr Diet. 1999:4:124-7.

27. Barr SI. Nutrition knowledge and selected nutritional practices of female recreational athletes. J Nutr Educ. 1986:4:167-74.

28. Davar V. Nutritional knowledge and attitudes towards healthy eating of college-going women hockey players. J Hum Ecol. 2012;2:119-24.

29. Torres-McGehee TM, Pritchett KL, Zippel D, Minton DM, Cellamare A, Sibilia M. Sports nutrition knowledge among collegiate athletes, coaches, athletic trainers, and strength and conditioning specialists. J Athl Train. 2012;47:205-11.

30. Jessri M, Jessri M, RashidKhani B, Zinn C. Evaluation of Iranian college athletes' sport nutrition knowledge. Int J Sport Nutr Exerc Metab. 2010; 3:257-63.

31. Trakman G, Forsyth A, Devlin B, Belski R. A systematic review of athletes' and coaches' nutrition knowledge and reflections on the quality of current nutrition knowledge measures. Nutrients. 2016:9:570-93.

32. Spronk I, Heaney SE, Prvan T, O'Connor HT. Relationship between general nutrition knowledge and dietary quality in elite athletes. Int J Sport Nutr Exerc Metab. 2015;25:243-51.

33. Parks RB, Helwig D, Dettmann J, Taggart T, Woodruff B, Horsfall K, Brooks MA. Developing a performance nutrition curriculum for collegiate athletics. J Nutr Educ Behav. 2016;6:419-24. e411

Ready to submit your research? Choose BMC and benefit from:

- fast, convenient online submission

- thorough peer review by experienced researchers in your field

- rapid publication on acceptance

- support for research data, including large and complex data types

- gold Open Access which fosters wider collaboration and increased citations - maximum visibility for your research: over $100 \mathrm{M}$ website views per year

At BMC, research is always in progress.

Learn more biomedcentral.com/submissions 